\title{
A DFT/TDDFT study on the mechanisms of direct and indirect photodegradation of tetrabromobisphenol $\mathrm{A}$ in water
}

\author{
Se Wang ${ }^{\text {a, b }}$, Zhuang Wang ${ }^{\text {a, * }}$, Ce Hao ${ }^{c}$, Willie J.G.M. Peijnenburg ${ }^{\text {b, d }}$ \\ a School of Environmental Science and Engineering, Collaborative Innovation Center of Atmospheric Environment and Equipment Technology (AEET), \\ Jiangsu Key Laboratory of Atmospheric Environment Monitoring and Pollution Control (AEMPC), Nanjing University of Information Science and Technology, \\ Nanjing 210044, China \\ ${ }^{\mathrm{b}}$ Institute of Environmental Sciences (CML), Leiden University, Leiden 2300 RA, the Netherlands \\ ' State Key Laboratory of Fine Chemicals, Dalian University of Technology, Dalian 116024, China \\ ${ }^{\mathrm{d}}$ National Institute of Public Health and the Environment, Center for the Safety of Substances and Products, Bilthoven 3720 BA, the Netherlands
}

\section{H I G H L I G H T S}

- Photodegradation mechanism of TBBPA with $\cdot \mathrm{OH}$ is $\mathrm{OH}$-addition and $\mathrm{Br}$-substitution.

- Photodegradation mechanisms of TBBPA with ${ }^{1} \mathrm{O}_{2}$ is $\mathrm{H}$ abstraction by ${ }^{1} \mathrm{O}_{2}$.

- $\mathrm{C}-\mathrm{Br}$ cleavage was observed in the optimized geometries of TBBPA in the $\mathrm{T}_{1}$ state.

- Direct photodegradation of TBBPA is debromination, $\mathrm{C}-\mathrm{C}$ cleavage, and cyclization.

\section{A R T I C L E I N F O}

\section{Article history:}

Received 17 October 2018

Received in revised form

1 December 2018

Accepted 11 December 2018

Available online 12 December 2018

Handling Editor: Jun Huang

\section{Keywords:}

Tetrabromobisphenol A

Photodegradation

. $\mathrm{OH}$

${ }^{1} \mathrm{O}_{2}$

DFT

\begin{abstract}
A B S T R A C T
Tetrabromobisphenol A (TBBPA) is the most widely used commercial brominated flame retardant. However, the mechanisms underlying the photodegradation of TBBPA remain unclear. Here we use density functional theory and time-dependent density functional theory to examine the photodegradation of the two species of TBBPA in water: TBBPA (neutral form) and TBBPA ${ }^{-}$(anionic form). The study includes direct photodegradation and indirect photodegradation of TBBPA with $\cdot \mathrm{OH}$ and ${ }^{1} \mathrm{O}_{2}$. The results of the calculations indicate that indirect photodegradation of TBBPA and TBBPA ${ }^{-}$with $\cdot \mathrm{OH}$ occurs via $\mathrm{OH}$-addition and $\mathrm{Br}$-substitution. All of the $\mathrm{OH}$-addition and $\mathrm{Br}$-substitution pathways are exothermic. Indirect photodegradation of TBBPA and TBBPA- by ${ }^{1} \mathrm{O}_{2}$ proceeds via $\mathrm{H}$ abstraction by ${ }^{1} \mathrm{O}_{2}$. $E_{\mathrm{a}}$ was higher for $\mathrm{H}$ abstraction of TBBPA than $\mathrm{H}$ abstraction of $\mathrm{TBBPA}^{-}$. The mechanisms for the direct photodegradation of TBBPA and TBBPA ${ }^{-}$include debromination, $\mathrm{C} 1-\mathrm{C} 7 / \mathrm{C} 7-\mathrm{C} 13$ cleavage, and cyclization. $\mathrm{C}-\mathrm{Br}$ cleavage was observed in the optimized geometries of TBBPA and $\mathrm{TBBPA}^{-}$at the lowest excited triplet state. However, high $E_{\mathrm{a}}$ values and an endothermic nature indicated that $\mathrm{C} 1-\mathrm{C} 7 / \mathrm{C} 7-\mathrm{C} 13$ cleavage and cyclization reactions were not the main pathways. $\mathrm{OH}$-adducts, $\mathrm{Br}$-substitution products, $\mathrm{H}-$ abstraction (by ${ }^{1} \mathrm{O}_{2}$ ) products, and debromination products were the main products of photodegradation of TBBPA. These findings provide useful information for risk assessment and pollution control of brominated flame retardants.
\end{abstract}

(C) 2018 Elsevier Ltd. All rights reserved.

\section{Introduction}

Tetrabromobisphenol A (TBBPA) is the most common commercial brominated flame retardant and is extensively used in various plastics, textiles, and electronics to improve a product's fire safety.

\footnotetext{
* Corresponding author.

E-mail address: zhuang.wang@nuist.edu.cn (Z. Wang).
}

A large amount of TBBPA gets released to the environment during products' manufacturing, use, and disposal. TBBPA has frequently been found in various environmental media including surface water, wastewater, suspended particulate matter, soil, sediment, and even food (Kim et al., 2016; Liu et al., 2016; Kotthoff et al., 2017; Gustavsson et al., 2018; Lopez et al., 2018). TBBPA has been identified as an environmental endocrine disruptor, and is a potentially persistent, bioaccumulative, and toxic compound (WHO, 1995; He et al., 2015; Zhang et al., 2012; Zhu et al., 2018). In recent years, 
much research has focused on TBBPA's environmental behavior and degradation pathways (Malkoske et al., 2016; Peng et al., 2017; Cheng and Hua, 2018; Han et al., 2018; Zhang et al., 2018b).

Owing to TBBPA's possible threats to aquatic environments and human health, it is urgent to investigate its transformation in water to evaluate its environmental risk. Photodegradation is an important transformation path for TBBPA in natural water environments, and this can occur directly and indirectly. Direct photodegradation refers to a process in which a TBBPA molecule absorbs a photon and yields a TBBPA molecule in an excited electronic state that is then degraded. In indirect photodegradation, TBBPA reacts with reactive oxygen species, including hydroxyl radicals $(\cdot \mathrm{OH})$ and singlet oxygen molecules $\left({ }^{1} \mathrm{O}_{2}\right)$. The reactive species $\cdot \mathrm{OH}$ and ${ }^{1} \mathrm{O}_{2}$ are normally present in natural bodies of water, and can be formed from photochemical reactions involving dissolved organic matter, nitrites, and nitrates, among others (Dong and Rosario-Ortiz, 2012).

A small number of studies have focused on the photodegradation of TBBPA via $\cdot \mathrm{OH}$ and ${ }^{1} \mathrm{O}_{2}$ (Eriksson et al., 2004; Bao and Niu, 2015; Wang et al., 2015b; Han et al., 2016). Wang et al. (2015b) reported that the photolysis of TBBPA could occur with ${ }^{1} \mathrm{O}_{2}$ in an aqueous solution under simulated-solar-light irradiation. The results of Han et al. (2016) revealed that debromination could occur during the photodegradation of TBBPA via reaction with $\cdot \mathrm{OH}$. Bao and Niu (2015) reported that TBBPA's main photodegradation pathways were debromination and the breakage of $\mathrm{C}-\mathrm{C}$ bonds. However, the mechanisms underlying these processes remain unclear. Moreover, TBBPA ( $\mathrm{p} K_{\mathrm{a}}=7.4$ ) (Han et al., 2016), which contains ionizable group $-\mathrm{OH}$, exhibits different dissociated states in natural water. Eriksson et al. (2004) reported that the rate of photodegradation of TBBPA at $\mathrm{pH} 8$ was six times higher than the rate at $\mathrm{pH}$ 6. However, the differences in photodegradation behavior of TBBPA's different dissociated states remain unclear.

In recent years, density functional theory (DFT) has been widely used to investigate the properties and environmental behavior of organic pollutants (Qu et al., 2012; Shi et al., 2015; Wang et al., 2015a; Xu et al., 2016; Zeng et al., 2016). In this study, we investigated the TBBPA's indirect photodegradation mechanisms with reactive oxygen species $\left(. \mathrm{OH}\right.$ and $\left.{ }^{1} \mathrm{O}_{2}\right)$ and the direct photodegradation mechanisms of TBBPA in water using DFT and timedependent density functional theory (TDDFT). In addition, we also studied the differences between the degradation mechanisms of TBBPA across different dissociated states.

\section{Computational methods}

All calculations were performed using the Gaussian 09 software package (Frisch et al., 2009). All geometries were optimized using DFT (Kohn et al., 1996) at the B3LYP/6-311 + G(d,p) level of theory (Becke, 1993). The solvent effects in water were considered in all calculations using the integral equation formalism of the polarized continuum model (IEFPCM) (Tomasi et al., 2005). Frequencies of all of the geometries were calculated at the same level to confirm all of the stationary points. The electronic absorption spectra calculations for the different dissociated states of TBBPA in water were carried out at the B3LYP/6-311++G(d,p) level of theory using TDDFT, which was considered an applicable method to calculate the excited state properties of molecules (Burke et al., 2005; Zhao and Han, 2009, 2010, 2012). Atom-charge calculations were examined based on the natural bond orbital (NBO) scheme at the B3LYP/6-311++G(d,p) level of theory, which was also used for spin-density calculations.

Geometry optimizations of the reactant (R), transition state (TS), intermediate (IM), and product (P) of the direct and indirect photodegradation pathways of TBBPA's different dissociated states were carried out at the B3LYP/6-311 $+\mathrm{G}(\mathrm{d}, \mathrm{p})$ level of theory at the lowest excited triplet states $\left(T_{1}\right)$ because the $T_{1}$ states were found to be long-lived photochemical reaction precursors for many compounds (Zhang et al., 2018a). Vibration analysis of TS was performed to confirm that the TS had a single imaginary vibrational frequency. Intrinsic reaction coordinate (IRC) calculations were applied at the same level of theory to confirm that each TS connected with the corresponding R and P (Fukui, 1981). Zero-point energy correction was carried out for all of the calculated energy values, including the reaction's activation energy $\left(E_{\mathrm{a}}\right)$ and enthalpy change $(\Delta H)$.

\section{Results and discussion}

\subsection{Optimized geometries of the species TBBPA and TBBPA}

TBBPA has two dominant species in natural water: the neutral form (TBBPA) and the anionic form ( $\left.\mathrm{TBBPA}^{-}\right)$. The optimized geometries of these species are shown in Fig. 1. TBBPA has $C_{2}$ symmetry, which causes the $\mathrm{C} 1-\mathrm{C} 7$ and $\mathrm{C} 7-\mathrm{C} 13$ bond lengths to be the same (1.542 A). Similarly, the bond lengths of C7-C14 and C7-C15 are equal, and the two benzene rings $-\mathrm{A}$ and $\mathrm{B}-$ share the same structural parameters. We mainly focus the following discussion of the photodegradation mechanisms of TBBPA by referring to benzene ring $\mathrm{A}$.

Although $\mathrm{C} 7-\mathrm{C} 14$ and $\mathrm{C} 7-\mathrm{C} 15$ have the same bond length (1.547 $\AA$ ) in $\mathrm{TBBPA}^{-}$, the structural parameters of the two benzene rings differ owing to $\mathrm{TBBPA}^{- \text {'s }} C_{1}$ symmetry. For instance, the bonds of $\mathrm{C} 9-\mathrm{Br} 3$ and $\mathrm{C} 11-\mathrm{Br} 4$ in benzene ring $\mathrm{B}$ are slightly longer than those of $\mathrm{C} 3-\mathrm{Br} 1$ and $\mathrm{C} 5-\mathrm{Br} 2$ in benzene ring $\mathrm{A}$. The $\mathrm{C} 10-\mathrm{O} 2$ bond in ring $\mathrm{B}(1.268 \AA)$ is notably shorter than the $\mathrm{C} 4-\mathrm{O} 1$ bond in ring $\mathrm{A}$ (1.353 $\AA$ ). In addition, the $\mathrm{C} 10-\mathrm{O} 2$ bond shows some characteristics of a $\mathrm{C}=\mathrm{O}$ bond.

\subsection{Mechanisms of indirect photodegradation of TBBPA and $\mathrm{TBBPA}^{-}$via $\cdot \mathrm{OH}$ in water}

The possible pathways for indirect photodegradation of TBBPA with $\cdot \mathrm{OH}$ are shown in Fig. 2; these mainly include addition and substitution reactions. There are five possible reactive sites on ring A: C1, C2, C3, C5, and C6. The addition of $\cdot \mathrm{OH}$ at sites C2 (Path C2) and C6 (Path C6) can lead to the intermediates C2_IM and C6_IM, respectively. The computed $E_{\mathrm{a}}$ values $(1.3 \mathrm{kcal} / \mathrm{mol})$ for these addition reactions (Path $\mathrm{C} 2$ and Path C6) were the lowest observed across all pathways. Hydrogen-abstraction reactions can further take place between $\cdot \mathrm{OH}$ and the $\mathrm{C} 2$ _IM and C6_IM intermediates to form the products C2_P and C6_P, respectively. The addition of $\cdot \mathrm{OH}$ at site C1 (Path C1) can form the intermediate C1_IM, which can further undergo $\mathrm{C} 1-\mathrm{C} 7$ cleavage and eventually form the products C1_Pa (4-hydroxy-2,6-dibromophenol) and C1_Pb. Analyses of spin density and NBO charge indicated that $\mathrm{C} 1$ _Pb was a neutral radical, which can further abstract $\mathrm{H}$ from its environment and form 2,6dibromo-4-isopropylphenol. C1_Pa and C1_Pb have been detected during TBBPA photodegradation experiments (Eriksson et al., 2004; Bao and Niu, 2015). The $E_{\mathrm{a}}$ value for the addition of $\cdot \mathrm{OH}$ at site $\mathrm{C} 1$ was $2.7 \mathrm{kcal} / \mathrm{mol}$ higher than that of the addition of $\cdot \mathrm{OH}$ at site $\mathrm{C} 2 /$ C6.

In addition, $\mathrm{Br}$ atoms in benzene ring $\mathrm{A}$ can be substituted by . OH (Path C3 and C5) to produce C3_P and C5_P. Analyses of NBO charge and spin density indicated that the C3_P and C5_P products were radical cations and that $\mathrm{Br}$ existed as an anion. Han et al. (2016) detected Br-substitution products during TBBPA photodegradation experiments with $\cdot \mathrm{OH}$. The $E_{\mathrm{a}}$ values for $\mathrm{Br}-$ substitution reactions (sites $\mathrm{C} 3$ and $C 5$ ) were higher than those of $\mathrm{OH}$-addition reactions at sites $\mathrm{C} 1, \mathrm{C} 2$, and $\mathrm{C} 6$ (except for the $\mathrm{OH}$ addition at $\mathrm{C} 1$ and the Br-substitution at $\mathrm{C} 5$ which had the same $E_{\mathrm{a}}$ value). This indicates that the $\mathrm{OH}$-addition pathways were, in 
TBBPA

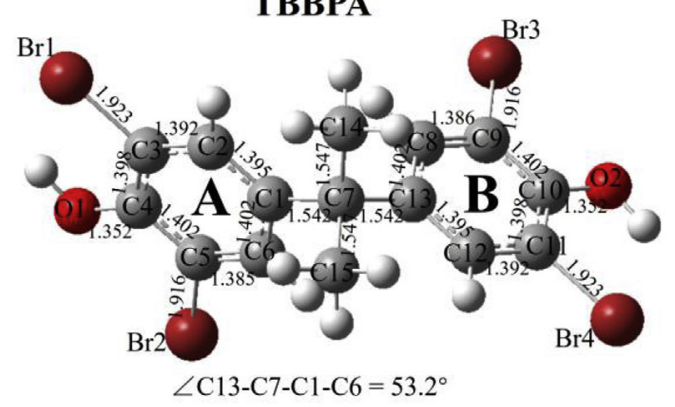

TBBPA $^{-}$

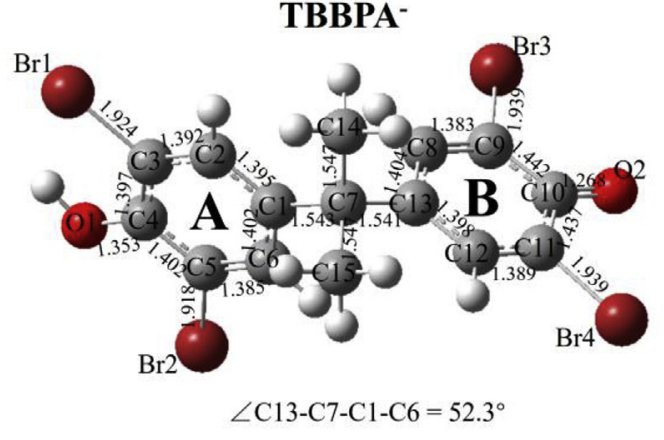

Fig. 1. Optimized geometries of the species TBBPA and TBBPA $^{-}$along with selected bond lengths $(\AA)$ and dihedral angles $\left({ }^{\circ}\right)$ in the ground state.

general, more favorable than the Br-substitution pathways. Fig. 2 shows that all pathways were predicted to be exothermic, with $\Delta H$ values ranging from -40.3 to $-9.9 \mathrm{kcal} / \mathrm{mol}$. The $\mathrm{C} 1 / \mathrm{C} 2 / \mathrm{C} 6 \cdots \mathrm{OH}$ distances in the TSs of the addition reactions at sites $\mathrm{C} 1, \mathrm{C} 2$, and $\mathrm{C} 6$ ranged from 2.071 to $2.103 \AA$, and were longer than those observed for the TSs of Br-substitution reactions (2.034 and $2.046 \AA$ at sites $\mathrm{C} 3$ and $\mathrm{C} 5$, respectively) (Fig. S1). In addition, $\cdot \mathrm{OH}$ can abstract the $\mathrm{H}$ atom connecting $01 / 02$ of TBBPA with corresponding $E_{\mathrm{a}}$ $(-0.1 \mathrm{kcal} / \mathrm{mol})$ and $\Delta H(-33.5 \mathrm{kcal} / \mathrm{mol})$ (Fig. S2).

The indirect photodegradation pathways for $\mathrm{TBBPA}^{-}$with $\cdot \mathrm{OH}$ are shown in Fig. 3 with the optimized TS, IM, and P geometries for each reaction shown in Fig. S3. These reactions followed $\mathrm{OH}-$ addition and Br-substitution pathways. The $E_{\mathrm{a}}$ value for the addition of $\cdot \mathrm{OH}$ at site $\mathrm{C} 2(1.2 \mathrm{kcal} / \mathrm{mol})$ was the lowest value observed across all pathways. The order of $E_{\mathrm{a}}$ values for the addition pathways by site was: $\mathrm{C} 6>\mathrm{C} 1>\mathrm{C} 8>\mathrm{C} 12>\mathrm{C} 13>\mathrm{C} 2$. All of the addition pathways were exothermic with $\Delta H$ ranging from -11.0 to $-2.3 \mathrm{kcal} / \mathrm{mol}$. The addition of $\cdot \mathrm{OH}$ at site $\mathrm{C} 1$ can lead to the formation of a $\mathrm{C} 1-\mathrm{OH}$ bond $\left(\mathrm{C}^{\mathrm{a}}{ }_{-} \mathrm{IM}\right)$, which can induce the breaking of $\mathrm{C} 1-\mathrm{C} 7$ and the generation of products $\mathrm{C} 1^{\mathrm{a}} \_\mathrm{Pa}$ and
$\mathrm{C}^{\mathrm{a}}{ }^{\mathrm{B}} \mathrm{Pb}$. The intermediates formed from addition reactions at sites $\mathrm{C} 2, \mathrm{C} 6, \mathrm{C} 8$, and $\mathrm{C} 12$ could further react with $\cdot \mathrm{OH}$ (via $\mathrm{H}$-abstraction reactions), with these reactions exhibiting low $E_{\mathrm{a}}$ values (there was no energy barrier within these reactions for Path $6^{\mathrm{a}}$ and Path $12^{\mathrm{a}}$ ). The order of the $E_{\mathrm{a}}$ values for the Br-substitution pathways was: Path $\mathrm{C} 9^{\mathrm{a}}<$ Path $\mathrm{C} 11^{\mathrm{a}}<$ Path $\mathrm{C} 5^{\mathrm{a}}<$ Path $\mathrm{C} 3^{\mathrm{a}}$. This order revealed that Br-substitution products were more likely to be formed from benzene ring $\mathrm{B}$ than from benzene ring $\mathrm{A}$. All of the Br-substitution pathways were also exothermic. However, the $\Delta H$ values for the Br-substitution pathways were notably lower than those for the addition pathways, suggesting that Br-substitution products were more stable than the adducts. The analyses of NBO charge and spin density indicated that the $\mathrm{Br}$ species produced by Br-substitution was an anion with a single negative charge $\left(\mathrm{Br}^{-}\right)$. In general, the $E_{\mathrm{a}}$ values for TBBPA's Br-substitution pathways were higher than those at $\mathrm{TBBPA}^{-}$'s sites 9 and 11 (ring $\mathrm{B}$ ) and lower than those at TBBPA $^{- \text {'s sites }} 3$ and 5 (ring A). Br-substitution reactions were more difficult to occur at ring $\mathrm{A}$ of $\mathrm{TBBPA}^{-}$than TBBPA, and more easy to occur at ring $\mathrm{B}$ of $\mathrm{TBBPA}^{-}$than TBBPA.

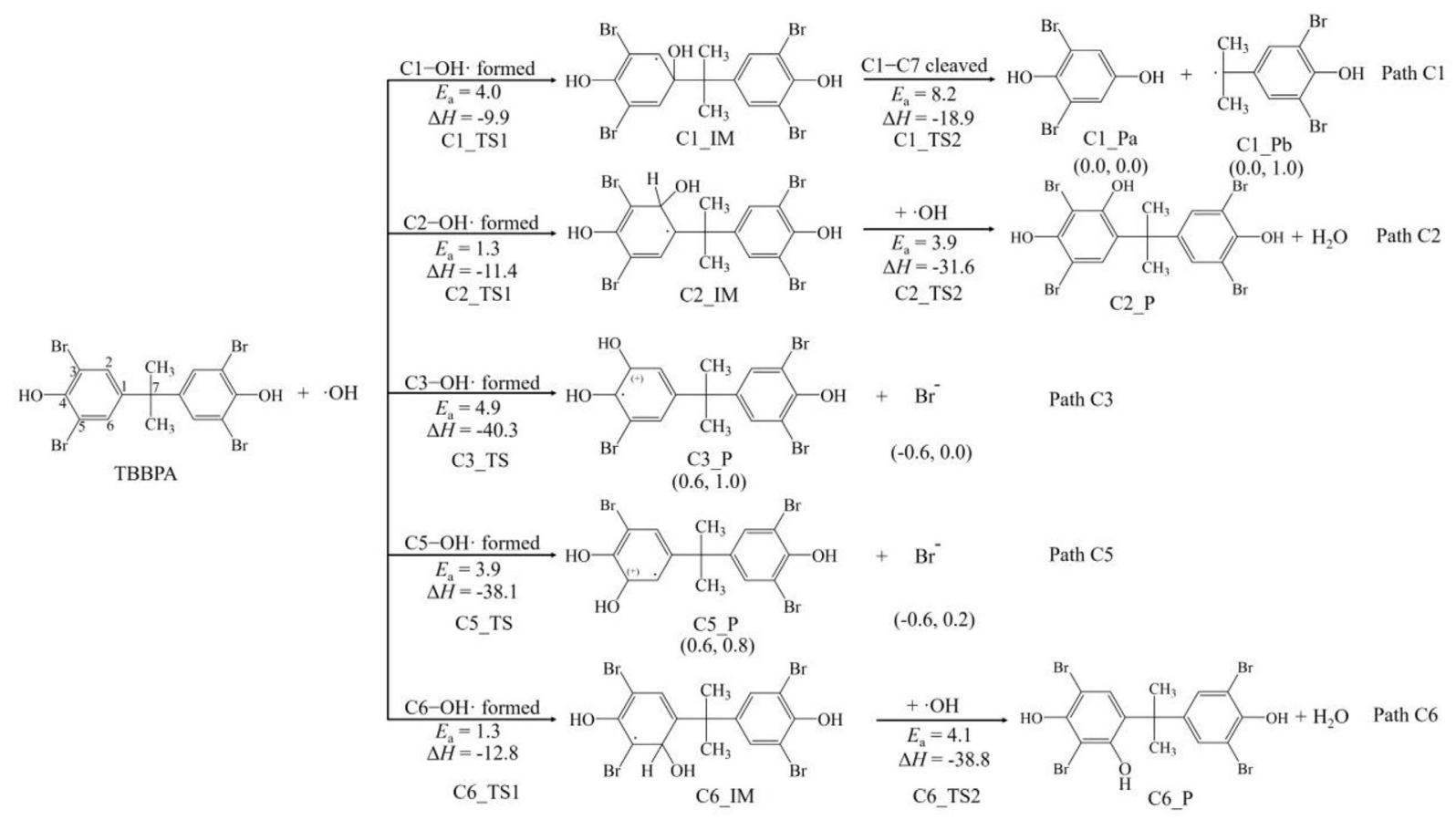

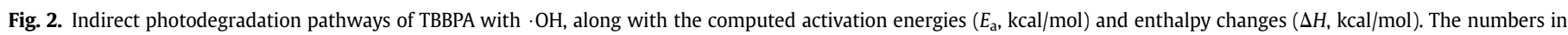
parentheses are the NBO charge and the electron spin density of the products (NBO charge, electron spin density). 
3.3. Mechanisms of indirect photodegradation of TBBPA and $\mathrm{TBBPA}^{-}$via ${ }^{1} \mathrm{O}_{2}$ oxidation in water

TBBPA and TBBPA ${ }^{-}$can undergo indirect photodegradation with ${ }^{1} \mathrm{O}_{2}$. The possible reaction pathways are shown in Fig. 4, and the corresponding optimized TS, IM, and P are shown in Fig. S4. For TBBPA, the $\mathrm{H}$ atom of the $\mathrm{O} 2-\mathrm{H}$ bond can be abstracted by ${ }^{1} \mathrm{O}_{2}\left(E_{\mathrm{a}}\right.$ : $11.9 \mathrm{kcal} / \mathrm{mol})$, which is a process that is endothermic $(\Delta H>0)$ (Fig. 4). Wang et al. (2015b) also suggested $\mathrm{H}$ abstraction by ${ }^{1} \mathrm{O}_{2}$ as the reaction mechanism following experimental photolysis of TBBPA with ${ }^{1} \mathrm{O}_{2}$. As shown in Fig. S4, during $\mathrm{H}$ abstraction, the bond length of $\mathrm{C} 10-\mathrm{O} 2$ (1.349 $\AA$ in the reactant) was shortened to $1.272 \AA$ in O_TS1 and $1.257 \AA$ in O_IM1 with these bonds exhibiting some characteristics of $\mathrm{C}=\mathrm{O}$ bonds. In addition, the $\mathrm{C} 1-\mathrm{C} 7$ bond in
O_IM2 could be further cleaved to form O_Pa and O_Pb. The $E_{\mathrm{a}}$ value of the $\mathrm{C} 1-\mathrm{C} 7$ cleavage was notably higher than that of $\mathrm{H}$ abstraction by ${ }^{1} \mathrm{O}_{2}$, revealing that the $\mathrm{C} 1-\mathrm{C} 7$ cleavage was the rate-determining step of the whole process. The product O_Pa is a radical with a spin density of 1.0 that can abstract $\mathrm{H}$ from its environment in the next step. Wang et al. (2015b) also detected O_Pa and O_Pb during experimental photolysis of TBBPA with ${ }^{1} \mathrm{O}_{2}$. In addition, intermediate O_IM2 may also further react with $\cdot \mathrm{H}$ or $\cdot \mathrm{OH}$ from its environment. For TBBPA ${ }^{-}$, the $E_{\mathrm{a}}$ and $\Delta H$ values for $\mathrm{H}$-abstraction by ${ }^{1} \mathrm{O}_{2}$ were both lower than those of TBBPA (by 6.5 and $7.1 \mathrm{kcal} / \mathrm{mol}$, respectively). This indicated that $\mathrm{H}$ abstraction by ${ }^{1} \mathrm{O}_{2}$ occurred more easily for $\mathrm{TBBPA}^{-}$. As with TBBPA, the C7-C13 cleavage was the rate-determining step for indirect photodegradation of $\mathrm{TBBPA}^{-}$ with ${ }^{1} \mathrm{O}_{2}$.

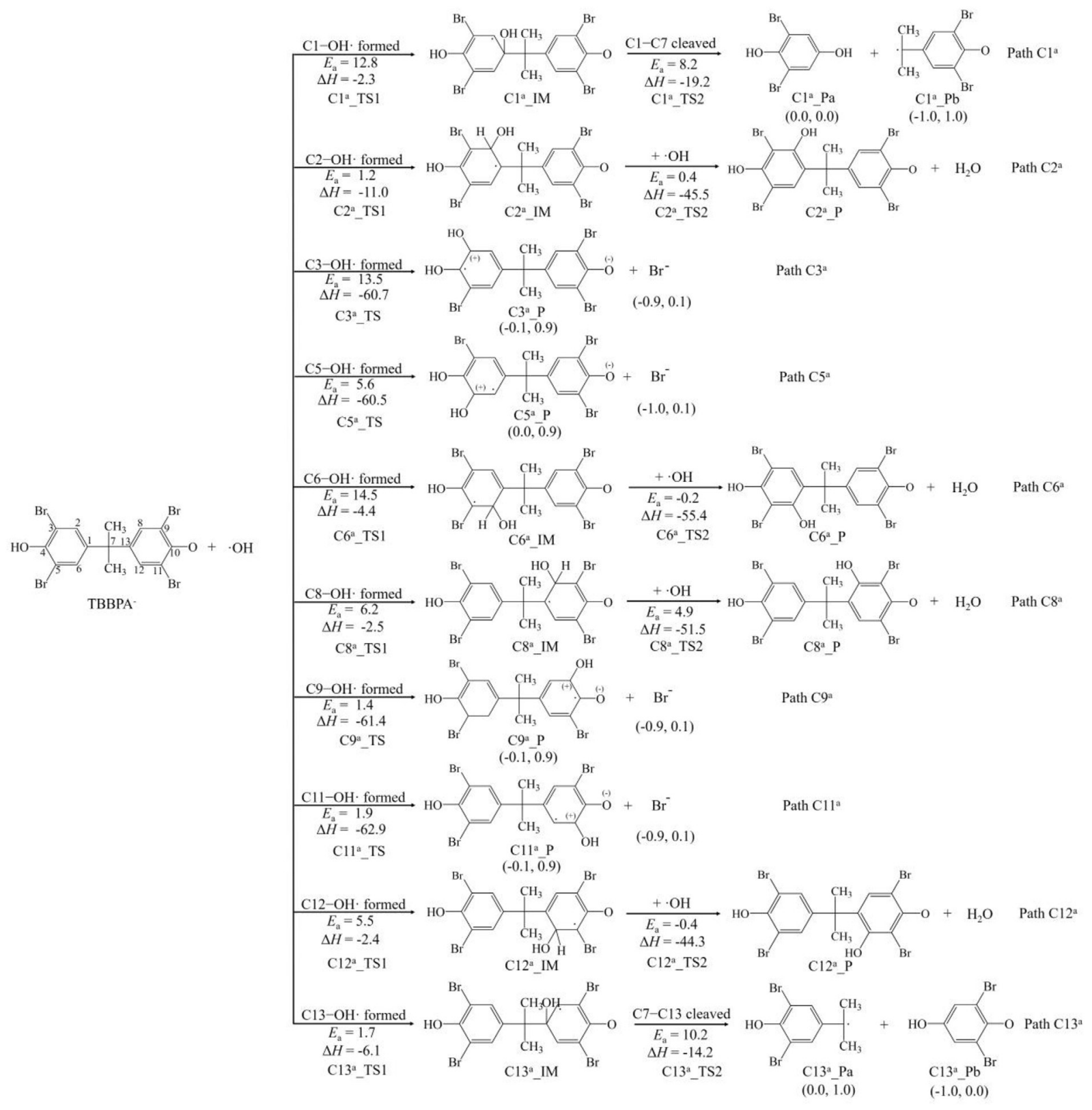

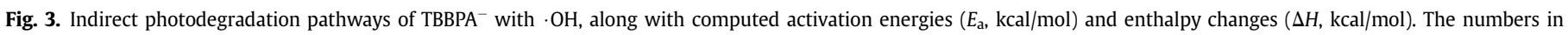
parentheses are the NBO charge and the electron spin density of the products (NBO charge, electron spin density). 

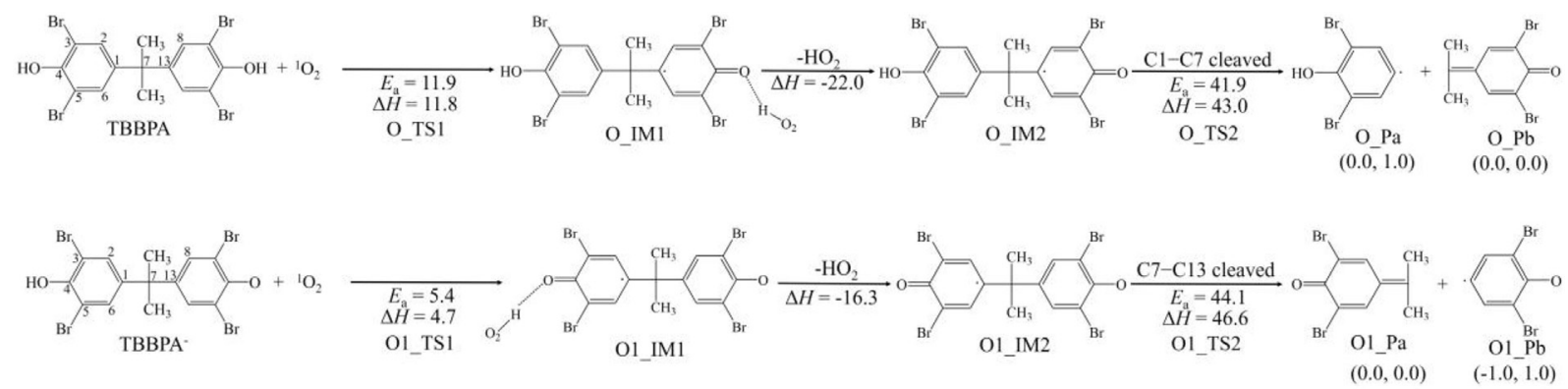

Fig. 4. Indirect photodegradation pathways of TBBPA and $\mathrm{TBBPA}^{-}$with ${ }^{1} \mathrm{O}_{2}$, along with computed activation energies $\left(E_{\mathrm{a}}\right.$, kcal/mol) and enthalpy changes $(\Delta H$, kcal $/ \mathrm{mol})$. The numbers in parentheses are the NBO charge and the electron spin density of the products (NBO charge, electron spin density).

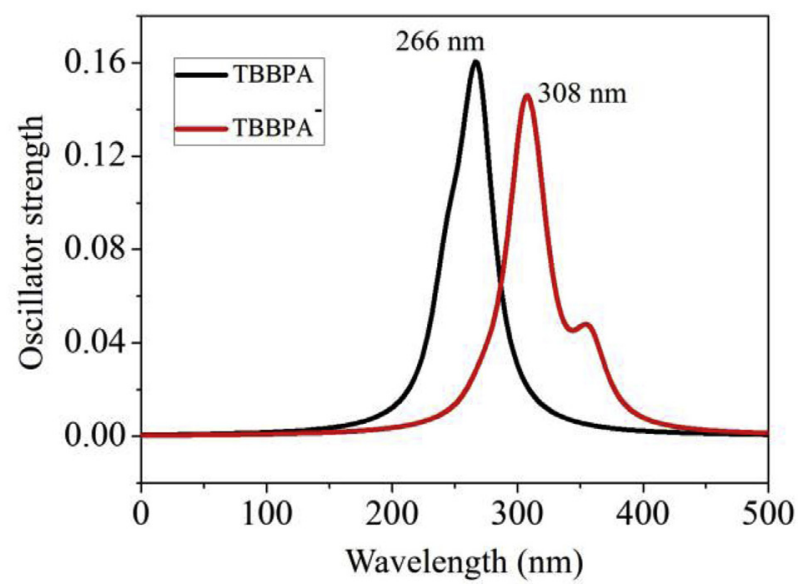

Fig. 5. Calculated electronic absorption spectra of the species TBBPA and TBBPA ${ }^{-}$with maximum absorption wavelength $(\mathrm{nm})$.

\subsection{Mechanisms of direct photodegradation of TBBPA and TBBPA in water}

The electronic absorption spectra of TBBPA and TBBPA $^{-}$are shown in Fig. 5. The calculated maximum absorption wavelengths of TBBPA and $\mathrm{TBBPA}^{-}$were 266 and $308 \mathrm{~nm}$, respectively. The corresponding experimental result is $309 \mathrm{~nm}$ (pH 7.8) (Wang et al., 2017). Direct photodegradation can occur for TBBPA and TBBPA $^{-}$in natural water because sunlight with a wavelength greater than $290 \mathrm{~nm}$ can reach the earth's surface. The $\mathrm{T}_{1}$ states of TBBPA and TBBPA $^{-}$were optimized (Fig. 6 ) because the $T_{1}$ states were found to be long-lived photochemical reaction precursors for many compounds (Wei et al., 2013). The results of the calculations indicate that one $\mathrm{C}-\mathrm{Br}$ bond was broken in the $\mathrm{T}_{1}$ state of TBBPA/TBBPA ${ }^{-}$ with the distance of the cleaved $\mathrm{C}-\mathrm{Br}$ in the range of 2.483-3.845 Å. In other words, debromination was likely to occur easily during direct photodegradation of TBBPA and TBBPA ${ }^{-}$. Wang et al. (2015b) and Bao and Niu (2015) detected debromination products in their TBBPA photolysis experiments. The TSs of debromination of TBBPA and $\mathrm{TBBPA}^{-}$were not obtained in the present work.

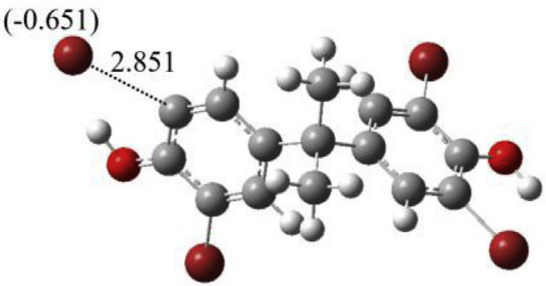

$0.0 \mathrm{kcal} / \mathrm{mol}$

TBBPA-T ${ }_{1}(1)$

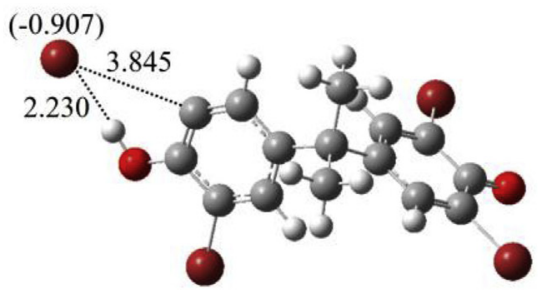

$0.0 \mathrm{kcal} / \mathrm{mol}$

TBBPA- $\mathrm{T}_{1}(1)$

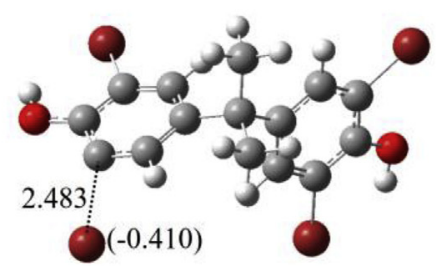

$4.2 \mathrm{kcal} / \mathrm{mol}$

TBBPA-T $_{1}(2)$

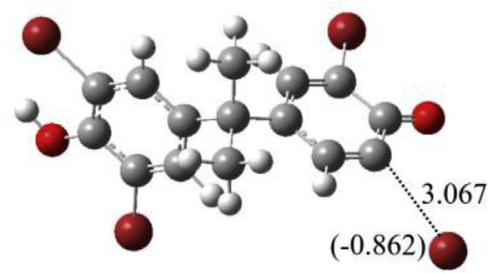

$6.0 \mathrm{kcal} / \mathrm{mol}$

TBBPA - $T_{1}(2)$
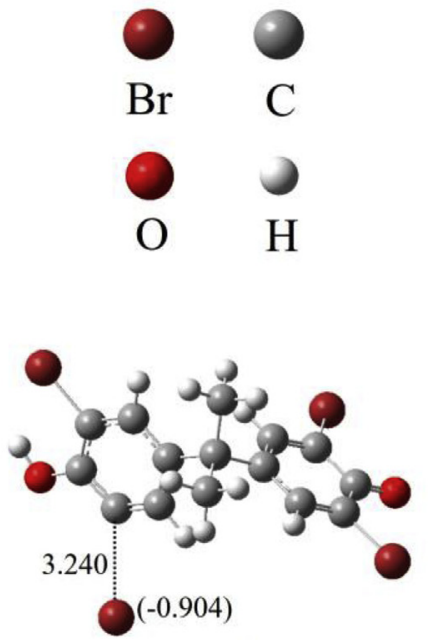

$6.2 \mathrm{kcal} / \mathrm{mol}$

TBBPA-T $\mathrm{T}_{1}$ (3)

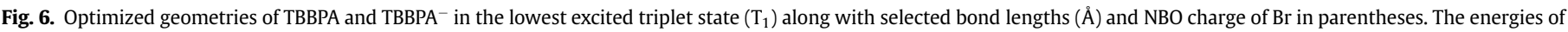
the optimized geometries are relative to the energies of the most stable geometry TBBPA-T $(1) / \mathrm{TBBPA}^{-}-\mathrm{T}_{1}(1)$. 
<smiles>CC(C)(c1cc(Br)c(O)c(Br)c1)c1cc(Br)c(O)c(Br)c1</smiles>

TBBPA

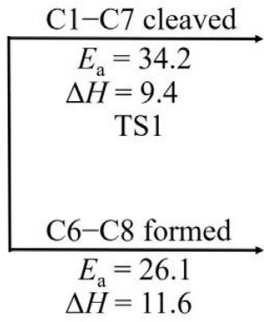

TS2<smiles>CC(C)(c1cc(Br)c(O)c(Br)c1)c1cc(Br)c(O)c(Br)n1</smiles>

TBBPA-

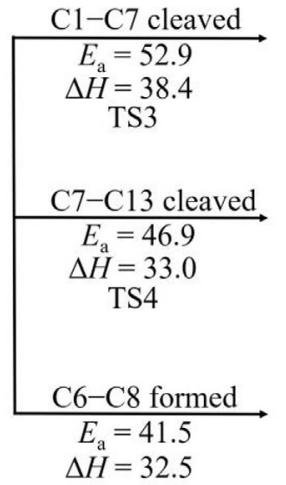

TS5<smiles>Oc1c(Br)cccc1Br</smiles><smiles>CC(C)(C)c1cc(Br)c(O)c(Br)c1</smiles>

Path (1)<smiles>CC1(C)c2cc(Br)c(O)c(Br)c2Cc2c1cc(Br)c(O)c2Br</smiles>

P2<smiles>CC(C)(C)c1cc(Br)c(O)c(Br)c1</smiles>

Path (3)

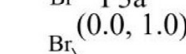

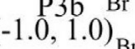

Path (2)<smiles>[R16]c1cc([C+]C(C)(C)c2cc(Br)c(O)c(Br)c2)cc(Br)c1Oc1ccccc1</smiles>

Path (5)

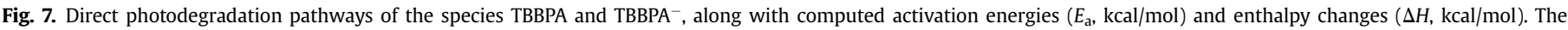
numbers in parentheses are the NBO charge and the electron spin density of the products (NBO charge, electron spin density).

In addition to debromination, two other possible reaction pathways ( $\mathrm{C}-\mathrm{C}$ cleavage and cyclization) for the direct photodegradation of TBBPA and TBBPA ${ }^{-}$are shown in Fig. 7, with their optimized TS and P geometries shown in Fig. S5. Pathways (1), (3), and (4) involve $\mathrm{C} 1-\mathrm{C} 7 / \mathrm{C} 7-\mathrm{C} 13$ cleavage, which can form radical products. The calculated spin densities of products P1a and P1b were both 1.0. The $E_{\mathrm{a}}$ values for the $\mathrm{C} 1-\mathrm{C} 7$ cleavage of TBBPA and TBBPA $^{-}$in the $\mathrm{T}_{1}$ state $(34.2$ and $52.9 \mathrm{kcal} / \mathrm{mol}$, respectively) were clearly higher than those of the $\mathrm{C} 1-\mathrm{C} 7$ cleavage caused by the aforementioned $\mathrm{OH}$-addition reactions. Their relatively high $E_{\mathrm{a}}$ values suggested that the $\mathrm{C} 1-\mathrm{C} 7 / \mathrm{C} 7-\mathrm{C} 13$ cleavage reactions in the direct photodegradation of TBBPA and TBBPA $^{-}$occurred less readily. Pathways (2) and (5) involved a cyclization reaction that was caused by the formation of a $\mathrm{C} 6-\mathrm{C} 8$ bond in the $\mathrm{T}_{1}$ state. The $E_{\mathrm{a}}$ values of the cyclization reactions for TBBPA and TBBPA $^{-}$were relatively high, suggesting that the cyclization reactions were not the main pathways followed during direct photodegradation of TBBPA and TBBPA ${ }^{-}$. Moreover, $\mathrm{C} 1-\mathrm{C} 7 / \mathrm{C} 7-\mathrm{C} 13$ cleavage and cyclization of TBBPA and $\mathrm{TBBPA}^{-}$were found to be endothermic.

\section{Conclusions}

This study provides an insight into the photodegradation mechanisms of the two species of TBBPA (TBBPA and TBBPA ${ }^{-}$) in water. These mechanisms relate to direct photodegradation and indirect photodegradation by reaction with $\cdot \mathrm{OH}$ and ${ }^{1} \mathrm{O}_{2}$. Calculation results indicated that indirect photodegradation of TBBPA and $\mathrm{TBBPA}^{-}$with $\cdot \mathrm{OH}$ could follow two mechanisms: $\mathrm{OH}$-addition and $\mathrm{Br}$-substitution. The addition of $\cdot \mathrm{OH}$ at site $\mathrm{C} 1 / \mathrm{C} 13$ can lead to the cleavage of the $\mathrm{C} 1-\mathrm{C} 7 / \mathrm{C} 7-\mathrm{C} 13$ bonds to form products such as 4 hydroxy-2,6-dibromophenol and 2,6-dibromo-4-isopropylphenol. The $E_{\mathrm{a}}$ values of the Br-substitution pathways for TBBPA were higher than those at TBBPA ${ }^{- \text {s }}$ sites 9 and 11 (ring B) and lower than those at TBBPA $^{- \text {'s sites }} 3$ and 5 (ring A). The calculations also indicated that indirect photodegradation of TBBPA and TBBPA ${ }^{-}$by reaction with ${ }^{1} \mathrm{O}_{2}$ involved $\mathrm{H}$ abstraction by ${ }^{1} \mathrm{O}_{2}$, which is in agreement with experimental results reported by Wang et al. (2015b). The calculated $E_{\mathrm{a}}$ value of the $\mathrm{H}$-abstraction process for TBBPA was higher than the calculated $E_{\mathrm{a}}$ value of TBBPA ${ }^{-}$. Direct photodegradation of TBBPA and TBBPA $^{-}$occurred via debromination, $\mathrm{C} 1-\mathrm{C} 7 / \mathrm{C} 7-\mathrm{C} 13$ cleavage, and cyclization. The $\mathrm{C}-\mathrm{Br}$ cleavage was observed in the optimized geometries of TBBPA and TBBPA $^{-}$in the $\mathrm{T}_{1}$ state. However, high $E_{\mathrm{a}}$ values suggested that the $\mathrm{C} 1-\mathrm{C} 7 /$ $\mathrm{C} 7-\mathrm{C} 13$ cleavage and cyclization reactions were not the main direct photodegradation pathways. Overall, $\mathrm{OH}$-adducts, Br-substitution products, $\mathrm{H}$-abstraction (by ${ }^{1} \mathrm{O}_{2}$ ) products, and debromination products were the main products of photodegradation of TBBPA. These findings illustrate that computational simulation can be an important tool for studying the mechanisms of aqueous photochemical transformation of emerging organic pollutants.

\section{Acknowledgments}

This research was supported by the National Natural Science Foundation of China (41601519) and the Natural Science Foundation of Jiangsu Province (BK20150891). Se Wang would like to thank the Chinese Scholarship Council (CSC) for financial support (201708320051).

\section{Appendix A. Supplementary data}

Supplementary data to this article can be found online at https://doi.org/10.1016/j.chemosphere.2018.12.087. 


\section{References}

Bao, Y., Niu, J., 2015. Photochemical transformation of tetrabromobisphenol A under simulated sunlight irradiation: kinetics, mechanism and influencing factors. Chemosphere 134, 550-556.

Becke, A.D., 1993. Density-functional thermochemistry. III. The role of exact exchange. J. Chem. Phys. 98, 5648-5652.

Burke, K., Werschnik, J., Gross, E.K.U., 2005. Time-dependent density functional theory: past, present, and future. J. Chem. Phys. 123, 062206.

Cheng, H., Hua, Z., 2018. Distribution, release and removal behaviors of tetrabromobisphenol A in water-sediment systems under prolonged hydrodynamic disturbances. Sci. Total Environ. 636, 402-410.

Dong, M., Rosario-Ortiz, F.L., 2012. Photochemical formation of hydroxyl radical from effluent organic matter. Environ. Sci. Technol. 46, 3788-3794.

Eriksson, J., Rahm, S., Green, N., Bergman, Å., Jakobsson, E., 2004. Photochemical transformations of tetrabromobisphenol A and related phenols in water. Chemosphere 54, 117-126.

Frisch, M.J., Trucks, G.W., Schlegel, H.B., Scuseria, G.E., Robb, M.A., Cheeseman, J.R. Scalmani, G., Barone, V., Mennucci, B., Petersson, G.A., Nakatsuji, H., Caricato, M., Li, X., Hratchian, H.P., Izmaylov, A.F., Bloino, J., Zheng, G., Sonnenberg, J.L., Hada, M., Ehara, M., Toyota, K., Fukuda, R., Hasegawa, J., Ishida, M., Nakajima, T. Honda, Y., Kitao, O., Nakai, H., Vreven, T., Montgomery, J.A., Peralta Jr., J.E., Ogliaro, F., Bearpark, M., Heyd, J.J., Brothers, E., Kudin, K.N., Staroverov, V.N., Kobayashi, R., Normand, J., Raghavachari, K., Rendell, A., Burant, J.C., Iyengar, S.S., Tomasi, J., Cossi, M., Rega, N., Millam, J.M., Klene, M., Knox, J.E. Cross, J.B., Bakken, V., Adamo, C., Jaramillo, J., Gomperts, R., Stratmann, R.E., Yazyev, O., Austin, A.J., Cammi, R., Pomelli, C., Ochterski, J.W., Martin, R.L., Morokuma, K., Zakrzewski, V.G., Voth, G.A., Salvador, P., Dannenberg, J.J., Dapprich, S., Daniels, A.D., Farkas, O., Foresman, J.B., Ortiz, J.V., Cioslowski, J., Fox, D.J., 2009. Gaussian 09 Package. Gaussian, Inc., Wallingford CT.

Fukui, K., 1981. The path of chemical reactions - the IRC approach. Accounts Chem. Res. 14, 363-368.

Gustavsson, J., Wiberg, K., Ribeli, E., Nguyen, M.A., Josefsson, S., Ahrens, L., 2018. Screening of organic flame retardants in Swedish river water. Sci. Total Environ. 625, 1046-1055.

Han, Q., Dong, W., Wang, H., Liu, T., Tian, Y., Song, X., 2018. Degradation of tetrabromobisphenol A by ferrate(VI) oxidation: performance, inorganic and organic products, pathway and toxicity control. Chemosphere 198, 92-102.

Han, S.K., Yamasaki, T., Yamada, K., 2016. Photodecomposition of tetrabromobisphenol A in aqueous humic acid suspension by irradiation with light of various wavelengths. Chemosphere 147, 124-130.

He, Q., Wang, X., Sun, P., Wang, Z., Wang, L., 2015. Acute and chronic toxicity of tetrabromobisphenol A to three aquatic species under different $\mathrm{pH}$ conditions. Aquat. Toxicol. 164, 145-154.

Kim, U., Lee, I., Oh, J., 2016. Occurrence, removal and release characteristics of dissolved brominated flame retardants and their potential metabolites in various kinds of wastewater. Environ. Pollut. 218, 551-557.

Kohn, W., Becke, A.D., Parr, R.G., 1996. Density functional theory of electronic structure. J. Chem. Phys. 100, 12974-12980.

Kotthoff, M., Rüdel, H., Jürling, H., 2017. Detection of tetrabromobisphenol A and its mono- and dimethyl derivatives in fish, sediment and suspended particulate matter from European freshwaters and estuaries. Anal. Bioanal. Chem. 409, 3685-3694.

Liu, D., Liu, J., Guo, M., Xu, H., Zhang, S., Shi, L., Yao, C., 2016. Occurrence, distribution, and risk assessment of alkylphenols, bisphenol A, and tetrabromobisphenol A in surface water, suspended particulate matter, and sediment in Taihu Lake and its tributaries. Mar. Pollut. Bull. 112, 142-150.

Lopez, M.G., Driffield, M., Fernandes, A.R., Smith, F., Tarbin, J., Lloyd, A.S., Christy, J., Holland, M., Steel, Z., Tlustos, C., 2018. Occurrence of polybrominated diphenylethers, hexabromocyclododecanes, bromophenols and tetrabromobisphenols A and S in Irish foods. Chemosphere 197, 709-715.

Malkoske, T., Tang, Y., Xu, W., Yu, S., Wang, H., 2016. A review of the environmental distribution, fate, and control of tetrabromobisphenol A released from sources. Sci. Total Environ. 569, 1608-1617.

Peng, X., Tian, Y., Liu, S., Jia, X., 2017. Degradation of TBBPA and BPA from aqueous solution using organo-montmorillonite supported nanoscale zero-valent iron. Chem. Eng. J. 309, 717-724.

Qu, R., Liu, H., Feng, M., Yang, X., Wang, Z., 2012. Investigation on intramolecular hydrogen bond and some thermodynamic properties of polyhydroxylated anthraquinones. J. Chem. Eng. Data 57, 2442-2455.

Shi, J., Qu, R., Feng, M., Wang, X., Wang, L., Yang, S., Wang, Z., 2015. Oxidative degradation of decabromodiphenyl ether (BDE 209) by potassium permanganate: reaction pathways, kinetics, and mechanisms assisted by density functional theory calculations. Environ. Sci. Technol. 49, 4209-4217.

Tomasi, J., Mennucci, B., Cammi, R., 2005. Quantum mechanical continuum solvation models. Chem. Rev. 105 (8), 2999-3093.

Wang, S., Song, X., Hao, C., Gao, Z., Chen, J., Qiu, J., 2015a. Elucidating tripletsensitized photolysis mechanisms of sulfadiazine and metal ions effects by quantum chemical calculations. Chemosphere 122, 62-69.

Wang, S., Wang, Z., Chen, M., Fang, H., Wang, D., 2017. Co-exposure of freshwater microalgae to tetrabromobisphenol A and sulfadiazine: oxidative stress biomarker responses and joint toxicity prediction. Bull. Environ. Contam. Toxicol. 99, 438-444.

Wang, X., Hu, X., Zhang, H., Chang, F., Luo, Y., 2015b. Photolysis kinetics, mechanisms, and pathways of tetrabromobisphenol $\mathrm{A}$ in water under simulated solar light irradiation. Environ. Sci. Technol. 49, 6683-6690.

Wei, X., Chen, J., Xie, Q., Zhang, S., Ge, L., Qiao, X., 2013. Distinct photolytic mechanisms and products for different dissociation species of ciprofloxacin. Environ. Sci. Technol. 47, 4284-4290.

WHO, 1995. Environmental Health Criteria 172. Tetrabromobisphenol a and Derivatives International Program on Chemical Safety. World Health Organization, Geneva, Switzerland.

Xu, F., Shi, X., Zhang, Q., Wang, W., 2016. Mechanism for the growth of polycyclic aromatic hydrocarbons from the reactions of naphthalene with cyclopentadienyl and indenyl. Chemosphere 162, 345-354.

Zeng, X., Zhang, X., Wang, Z., 2016. Theoretical study on the OH-initiated oxidation mechanism of polyfluorinated dibenzo-p-dioxins under the atmospheric conditions. Chemosphere 144, 2036-2043.

Zhang, H., Wei, X., Song, X., Shah, S., Chen, J., Liu, J., Hao, C., Chen, Z., 2018a. Photophysical and photochemical insights into the photodegradation of sulfapyridine in water: a joint experimental and theoretical study. Chemosphere 191, 1021-1027.

Zhang, K., Huang, J., Zhang, W., Yu, Y., Deng, S., Yu, G., 2012. Mechanochemical degradation of tetrabromobisphenol A: performance, products and pathway. J. Hazard Mater. 243, 278-285.

Zhang, X., Zhang, H., Xiang, Y., Hao, S., Zhang, Y., Guo, R., Cheng, X., Xie, M., Cheng, Q., Li, B., 2018b. Synthesis of silver phosphate/graphene oxide composite and its enhanced visible light photocatalytic mechanism and degradation pathways of tetrabromobisphenol A. J. Hazard Mater. 342, 353-363.

Zhao, G.-J., Han, K.-L., 2009. Excited state electronic structures and photochemistry of heterocyclic annulated perylene (HAP) materials tuned by heteroatoms: S, Se, N, O, C, Si, and B. J. Phys. Chem. 113, 4788-4794.

Zhao, G.-J., Han, K.-L., 2010. pH-Controlled twisted intramolecular charge transfer (TICT) excited state via changing the charge transfer direction. Phys. Chem. Chem. Phys. 12, 8914-8918.

Zhao, G.-J., Han, K.-L., 2012. Hydrogen bonding in the electronic excited state. Accounts Chem. Res. 45, 404-413.

Zhu, B., Zhao, G., Yang, L., Zhou, B., 2018. Tetrabromobisphenol A caused neurodevelopmental toxicity via disrupting thyroid hormones in zebrafish larvae. Chemosphere 197, 353-361. 